\title{
Chronotype: a review of the advances, limits and applicability of the main instruments used in the literature to assess human phenotype
}

\author{
Cronotipo: uma revisão dos avanços, limites e aplicabilidade dos principais \\ instrumentos utilizados na literatura para avaliar o fenótipo humano
}

\author{
Rosa Levandovski, ${ }^{1}$ Etianne Sasso, ${ }^{2}$ Maria Paz Hidalgo ${ }^{3}$
}

\begin{abstract}
The study of circadian typology differences has increased in the last few years. As a result, new instruments have been developed to estimate the individual circadian phase of temporal human behavior, also referred as chronotype. The current review was conducted to evaluate the differences among the questionnaires most frequently used to assess chronotype: the MorningnessEveningness Questionnaire (MEQ), the Composite Scale of Morningness (CSM), and the Munich Chronotype Questionnaire (MCTQ). Each instrument evaluates a different aspect of chronotype. MEQ is considered to evaluate the phase preferences of individual behavior over a 24-hour day, while MCTQ measures the phase of sleep positions for both free and work days. CSM is similar to MEQ, but is more sensitive to measure shift work. The concept of chronotype has been used to refer to phase positions or phase preferences in the literature reviewed. Most of the time this is a consequence of different interpretations: it is not clear whether phase preferences are a direct manifestation of the individual's internal clock or a result of external cues, e.g., social interaction (including the alarm clock). Also, phase preferences are not uniform throughout life. Therefore, a single assessment, not taking age into consideration, will not accurately describe the sample. We suggest that MCTQ is the best instrument for investigators dealing with desynchronization and as an instrument for sleep phase. Conversely, if the goal is to assess characteristics that change under specific situations chronotype -, the MEQ should be used.
\end{abstract}

Keywords: Chronobiology phenomena, circadian rhythm, morningness, eveningness, review.

\section{Resumo}

O estudo das diferenças de tipologia circadiana tem aumentado nos últimos anos. Como resultado, novos instrumentos têm sido desenvolvidos para estimar as preferências interindividuais de fase circadiana, denominada de cronotipo, responsável pela organização temporal do processo de regulação do organismo. O objetivo desta revisão foi avaliar as diferenças dos principais questionários utilizados para avaliar cronotipos: o Questionário de Matutinidade e Vespertinidade (Morningness-Eveningness Questionnaire, MEQ), o Composite Scale of Morningness (CSM) e o Questionário de Cronotipo de Munique (Munich Chronotype Questionnaire, MCTQ). Cada instrumento avalia um aspecto diferente dos cronotipos. Considera-se que o MEQ avalia as preferências de fase do comportamento individual ao longo de um dia de 24 horas, ao passo que o MCTQ mede a posição da fase de sono tanto em dias livres como em dias de trabalho. O CSM é semelhante ao MEQ, mas é mais sensível para ser utilizado em indivíduos que realizam trabalho em turnos. $\mathrm{O}$ conceito de cronotipo tem sido utilizado para se referir a posições de fase ou preferências de fase na literatura revisada. Na maioria das vezes, isso é consequência de diferentes interpretações: não está claro se as preferências de fase são uma manifestação direta do relógio interno do indivíduo ou um resultado de sinais externos, como por exemplo, interação social (incluindo o uso de despertador). Além disso, as preferências de fase não são uniformes ao longo da vida. Sendo assim, uma única avaliação, sem levar em consideração a idade do indivíduo nos escores utilizados nessas escalas, não descreverá a amostra com precisão. Sugerimos, através desta revisão, que o MCTQ deve ser considerado como instrumento para investigações que lidam com dessincronização e como instrumento de medida de fase de sono. Por outro lado, se o objetivo é avaliar características que mudam em determinadas situações - cronotipo -, o MEQ deve ser utilizado.

Descritores: Fenômenos cronobiológicos, ritmo circadiano, matutino, vespertino, revisão.

\footnotetext{
1 PhD, Pharmacist, Laboratório de Cronobiologia, Hospital de Clínicas de Porto Alegre (HCPA)/Universidade Federal do Rio Grande do Sul (UFRGS), Porto Alegre, RS, Brazil. Programa de Pós-Graduação em Ciências Médicas: Psiquiatria, UFRGS. ${ }^{2}$ MSc, Laboratório de Cronobiologia, HCPA/UFRGS. Programa de PósGraduação em Ciências Médicas: Psiquiatria, UFRGS. ${ }^{3}$ MD, PhD. Professor, Laboratório de Cronobiologia, HCPA/UFRGS. Programa de Pós-Graduação em Ciências Médicas: Psiquiatria, UFRGS. Departamento de Psiquiatria e Medicina Legal, Faculdade de Medicina, UFRGS.

Financial support: Fundo de Incentivo à Pesquisa - Hospital de Clínicas de Porto Alegre (FIPE-HCPA), Conselho Nacional de Desenvolvimento Científico e Tecnológico (CNPq), Fundação de Amparo à Pesquisa do Estado do Rio Grande do Sul (FAPERGS), and Programa Nacional de Pós-Doutorado - Coordenação de Aperfeiçoamento de Pessoal de Nível Superior (PNPD/CAPES).

Submitted Jul 15 2012, accepted for publication Sep 21 2012. No conflicts of interest declared concerning the publication of this article.

Suggested citation: Levandovski R, Sasso E, Hidalgo MP. Chronotype: a review of the advances, limits and applicability of the main instruments used in the literature to assess human phenotype. Trends Psychiatry Psychother. 2013;35(1):3-11.
} 


\section{Conception and development of the chronotype construct}

The interest in the study of individual typology (chronotype) has increased in the last few years, as a way to understand the temporal organization of the regulatory processes of the body. Chronotype is an attribute of human beings that reflects their individual circadian phase. These phases reveal at what time of the day the individual's physical functions, hormone levels, body temperature, cognitive faculties, and eating and sleeping patterns are active. Phase differences, measured over a period of 24 hours for the variables listed above, reflect different preferences among individuals. Phase preferences have a normal distribution in the general population, regardless of geographical region, cultural aspects, or the instrument used to assess this typology..$^{1-5}$

There is some discussion about the concept of chronotype in the literature. The phenomenon is commonly reduced to sleeping habits, as some individuals prefer to go to bed early and wake up early, and others prefer to go to bed late and wake up late. ${ }^{1}$ Another definition of chronotype present in the literature states that a single phase reference point is used to determine the circadian rhythm's entrainment of the endogenous timing system to a period of 24 hours. ${ }^{3}$ Other studies, in turn, describe chronotype as a phase of entrainment that denotes the relationship between external and internal time, i.e., the phase angle between an external Zeitgeber rhythm (e.g., light/dark cycle) and an output rhythm (e.g., sleep-wake cycle). ${ }^{3}$ One critique of this view is that the morningnesseveningness score reflects preferences rather than a measure of the phase of entrainment, and therefore cannot be considered to measure chronotype.

Differences in circadian rhythm parameters have been reviewed by Kerkhof. ${ }^{4}$ According to that author, the results found in different studies are not directly comparable because they rely on varying methods of analysis rather than on a uniform measurement over a 24-hour period. ${ }^{4}$ The classification of a chronotype should take into account the measurement of different rhythms in each subject. It is not possible to measure these rhythms directly using the scales currently available, and attempts to do so have resulted in indirect estimates of each subject's rhythm in relation to other individuals, or to an external rhythm, e.g., the light/dark cycle. Even though chronotype should be considered as an indirect estimation of circadian rhythm (phenotype), it remains unclear to what extent it is a direct manifestation of the individual's internal clock or a result of external cues, e.g., social interaction (including the alarm clock).

Chronotype as a human trait is based on selfreported accounts as to when individuals prefer to perform certain activities. Some of the criticisms of these self-report questionnaires include the fact that total scores may not be an appropriate measure of circadian rhythms and chronotypes as multidimensional constructs. With this in mind, new questionnaires have been developed. However, rather than resolving the issue, the influx of questionnaires has led to further problems, because these new instruments evaluate different aspects of the same phenomenon. Moreover, these new measurements use arbitrary cutoff points to determine diurnal preference, which may be deemed as unreliable. The present review was conducted in an attempt to understand these concepts in greater detail and to point out the differences and applicability of the questionnaires most widely used.

The current study evaluated experimental, observational, double-blind, controlled randomized clinical trials. Studies published in English, Portuguese, Spanish, French, and Italian, from 1960 to January 2011, were searched on the MEDLINE and Cochrane databases. The following keywords were used: morningness, morning-type, and chronotype. A total of 437 articles were retrieved. Research on biological rhythms became increasingly popular in the 20th century, causing an increase in the number of studies in the last few years, as illustrated in Figure 1. Studies were selected for a more detailed analysis if they included a questionnaire to evaluate chronotype or mentioned, in the abstract, an eveningnessmorningness dimension of behavioral or sleep cycle preferences. A total of 232 articles were selected at this stage. Table 1 (online supplementary material) provides a summary of the articles analyzed.

\section{Scales most frequently used in the literature}

\section{Horne and Ostberg Morningness-Eveningness Questionnaire (MEQ)}

The first validated questionnaire developed to assess morningness-eveningness dimensions was developed by Horne \& Ostberg in 1976 and was called the Morningness-Eveningness Questionnaire (MEQ). ${ }^{1}$ It was used to estimate phase preferences in circadian rhythms based on self-description by participants, identifying whether individuals were characterized as morning types or evening types as a continuous variable.

The MEQ comprises 19 questions with Likert-type responses. Questions evaluate the time that individuals get up and go to bed, self-reported preferred times for physical and mental activity, and also the individual's subjective alertness. Questions are mostly subjective, 


\section{Number of studies}

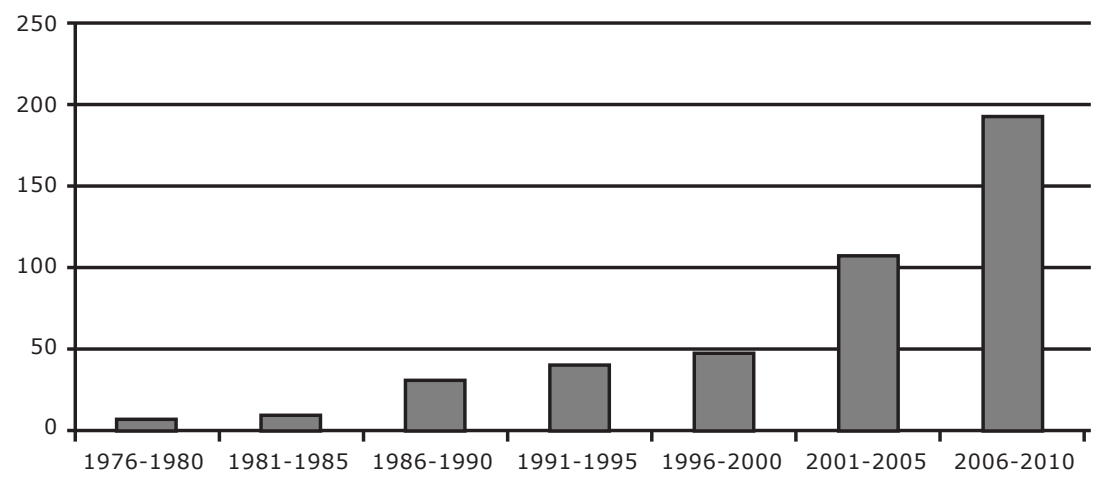

Five-year periods

Figure 1 - Number of studies found using the keywords morningness, morning-type, and chronotype, evidencing a growing importance of the topic in more recent years

relating sleep and activity times to a personal "feeling best" rhythm, to the habits of others (e.g., "I get up later than most people"), or to hypothetical situations (e.g., "At approximately what time would you get up if you were entirely free to plan your day?"). Some questions ask for given ranges of time (e.g., "At what time in the evening do you feel tired and in need of sleep?"). Morningness-eveningness is expressed using a score that may range from 16 to 86 , with a higher score indicating a stronger morningness preference. The MEQ was originally validated for a young adult population (18-32 years) ${ }^{1}$ and subsequent studies have found that the distribution of results in this age group is skewed towards eveningness. 5,6

In the first validation, body temperature peaked significantly earlier for morning types than for evening types, and between the two extremes for intermediate types. ${ }^{1}$ According to Horne \& Ostberg, ${ }^{1}$ evening types tended to go to bed 99 minutes later than morning types, on average, and morning types woke up an average of 114 minutes earlier than evening types. Bed time and waking time were both significantly correlated with morningness-eveningness. ${ }^{1}$ Since then, the MEQ score has been correlated with actual behavioral and physiological rhythms for various changes in the body, e.g., temperature, ${ }^{7,8}$ melatonin, and cortisol.9,10

The MEQ has been used to determine a tendency towards morning-type, evening-type, or intermediatetype preferences. ${ }^{11-14}$ In 2004, Taillard et al. revised the MEQ scoring system using a middle-aged population. ${ }^{15}$ The results of that study indicated that a bed time of 11:30 p.m. could be indicative of a morning type in a student population but of an evening type in adults aged 40 to 50 years. ${ }^{15}$

\section{Reduced Version of the Morningness- Eveningness Questionnaire (rMEQ)}

One of the problems identified with the MEQ instrument was its length, which would often prevent individuals from completing the questionnaire in full. In an attempt to solve the problem, Adan \& Almirall ${ }^{16}$ adapted the original questionnaire by Horne \& Ostberg into a shortened version. They called this new version the Reduced MEQ, or rMEQ.

The rMEQ comprises five questions based on the original version of the MEQ. Questions 1 through 3 ask subjects to indicate the time of the day when they feel at their best, the time they prefer to get up, and the time they prefer to go to bed. Question 4 is related to the degree of tiredness perceived in the first half hour after waking. Finally, in question 5, subjects are asked to indicate their morningness or eveningness preferences. The rMEQ has proven to be a quick and reliable measure, with adequate inter-item correlation and validity. ${ }^{16,17} \mathrm{~A}$ more recent study has validated the instrument in a population mostly comprised of young students. ${ }^{18}$

\section{Composite Scale of Morningness (CSM)}

The Composite Scale of Morningness (CSM) results from an effort to extract the best items from three morningness questionnaires. ${ }^{19}$ It comprises 13 questions with Likert-type responses, designed to determine an individual's preference for different activities and how easy it is for him/her to wake up in the morning (e.g., times to get up and to go to bed, how easy it is to rise 
at 6:00 p.m.). The scale also includes nine items from the $\mathrm{MEQ}^{1}$ and four items from the Diurnal Type Scale (DTS). ${ }^{20}$ Total CSM scores may range from 13 to $55 .{ }^{19}$ The original cutoff points were set at the 10th and 90th percentiles and yielded three categories according to CSM scores: evening type, scores $\leq 22$; intermediate type, $23 \leq$ score $\leq 43$; and morning type, scores $\geq 44$. $^{19}$

The internal consistency of the CSM shows alpha = 0.87 , with psychometric properties comparable to those of the MEQ and DTS. ${ }^{19}$ In addition, the CSM has shown good psychometric properties when used with both students and workers. Finally, CSM scores have shown to remain stable over time and not to change when subjects are exposed to night work and shift work. Scale reliability in a French sample of nursing students ( $n=356$; mean age of $25.60 \pm 6.10$ years; range: $18-54$ ) as observed by Caci et al. ${ }^{21}$ showed alpha values of 0.87 , equal to those reported Smith et al. ${ }^{19}$ Greenwood also observed good psychometric properties of the CSM in Australian students and individuals who worked rotating shifts. ${ }^{22}$ According to Smith et al., ${ }^{19}$ the composite questionnaire provided a better psychometric evaluation than MEQ. Notwithstanding, the composite questionnaire does not yet appear to have been validated by physiological markers of the biological clock, such as melatonin and cortisol levels or body temperature.

\section{Munich Chronotype Questionnaire (MCTQ)}

The Munich Chronotype Questionnaire (MCTQ) ${ }^{23}$ is a new method that assesses chronotype using self-reported individual sleep phases. The MCTQ comprises separate questions about people's sleep times on both work days and free days. Chronotype is calculated based on the midpoint between sleep onset and wake up (mid-sleep). Mid-sleep is set as the phase reference point for sleep on free days, i.e., days with no work or social obligations. ${ }^{24}$ Except for those with extreme early chronotypes, individual sleep times show large differences between work and free days, with most subjects accumulating sleep debt over their work days. Therefore, their midsleep on free days should be corrected to account for the sleep deficit accumulated during work days. ${ }^{24}$

According to the authors, the MCTQ provides a quantitative measure of chronotype as a continuous variable and is based on sleep behavior rather than sleep preferences. ${ }^{25}$ As a result, the MCTQ is not categorical (based on scores), but provides population-specific continuous distributions, with early and late chronotypes falling on either tail of the distribution. This allows to define population-specific thresholds and thus categorize chronotypes.

The MCTQ was primarily developed to study the epidemiology of human chronotypes, and has been validated by Zavada et al. ${ }^{26}$ using the MEQ as reference. Mid-sleep times assessed using the MCTQ were highly correlated with sleep preference scores obtained with the MEQ $(r=-0.73) .{ }^{26}$ The main difference between these two instruments is that the MEQ determines morningness and eveningness preferences based on self-reports of the respondents' preferred times of the day for activity and rest rather than their effective sleep-wake times, ${ }^{27}$ whereas the MCTQ assesses the mid-sleep phase of sleep on free days. In other words, one measures a preference that can be viewed as a personality trait, and the other measures actual real life habits, which can be viewed as a state.

The MCTQ has some limitations. The first limitation is that, because the instrument does not apply to all populations, a strict set of criteria is necessary to exclude certain groups, e.g., people who use an alarm clock on free days. The second limitation revolves around the calculations required to correct for acquired sleep debt (the instrument result cannot be obtained by simply adding individual scores). Combined, these limitations make the MCTQ difficult to use in studies with an unknown distribution of sleep patterns. Also, the MCTQ has not yet been validated for samples of shift workers.

\section{Limitations of the scales used to evaluate chronotypes}

\section{Normative cutoff points inappropriate for different samples}

At present, the questionnaire most widely used to assess morningness-eveningness preferences is the MEQ. However, MEQ scores do not produce consistent categories for samples of different ages. The cutoff points determined in the original publication ${ }^{1}$ are based on a sample of young adults (18 to 32 years old).

The relationship between morningness-eveningness scores and usual wake times has been demonstrated. Duffy et al. ${ }^{9}$ investigated intrinsic circadian period and self-reported diurnal preference using morning or evening activity patterns and usual waking time as indicators. The authors found a significant positive correlation between intrinsic circadian period and usual waking time and a significant negative correlation between intrinsic circadian period and self-assessed morningness-eveningness scores. Shorter periods were associated with morningness preferences, and longer periods, with eveningness preferences.

MEQ scores are inconsistent across younger and older age groups and also across different populations. ${ }^{14,28}$ Recently, Taillard et al. ${ }^{15}$ validated the instrument in a population of middle-aged French workers (mean 
age: $51.2 \pm 3.2$ years). Paine et al., ${ }^{28}$ in turn, found that morning types predominated when morningnesseveningness frequency was compared using Horne and Ostberg's MEQ scores, ${ }^{1}$ whereas the criteria validated by Taillard et al. ${ }^{15}$ provided a more balanced distribution of chronotypes.

Caci et al. ${ }^{17}$ also compared the frequencies of the three chronotype categories using the criteria proposed for the original MEQ $(<42,42-58$, and $>58)$, for the rMEQ ( $<12,12-17$, and $>17)$, and for the CSM (10th percentile/90th percentile), with higher scores indicating a stronger morning preference in all three instruments. The authors found similar proportions of subjects categorized as being evening-type, intermediate-type, and morning-type (95.0, 75.3, and $85.7 \%$, respectively) across both instruments. Notwithstanding, it should be noted that the proportion of the classification obtained on both instruments was the same, and this likely occurred because the CSM is based on the MEQ. When using the CSM and rMEQ, proportions were 95.0, 74.1, and $53.1 \%$; and with the MEQ and rMEQ, 84.6, 84.4, and $45.8 \% .{ }^{17}$ The comparison of proportions obtained with the different questionnaires emphasizes a recurrent problem with the use of cutoff scores: the values available for all three instruments result in a very poor concordance of chronotypes, casting serious doubt on the coarsely categorized scores used to reflect the position of an individual over the morningness continuum. One possible explanation for this classification problem could be an abnormal sample distribution, as observed in Greenwood's work using the CSM (that the age sample was negatively skewed, probably influencing the proportion of individuals classified as evening, intermediate, or morning types). ${ }^{22}$ Using the original CSM scores suggested by Smith et al., ${ }^{19}$ $2.4 \%$ of the individuals were considered to be evening types, $84.4 \%$ intermediate types, and $13.2 \%$ morning types. ${ }^{29}$ Mathematical algorisms have been proposed to account for the effects of age, gender, and culture on categorization results. ${ }^{30}$

\section{Influence of social cues and work schedules not taken into account}

Assessing chronotype in shift workers is difficult. Depending on their work schedules, people have to change their sleeping habits weekly by several hours; consequently, the measurement of diurnal preferences may be masked by work activity. ${ }^{31-33}$ Additionally, the psychometric adequacy of CSM is questionable. Torsvall \& Akersted $\mathrm{A}^{20}$ developed a shift work scale based on sleep preferences on both free and work days. The authors had criticized the MEQ because they deemed some of its items as inappropriate for workers on irregular schedules. Horne \& Ostberg's questionnaire ${ }^{1}$ is prone to be used with the self-report technique (e.g., perceived alertness), and was validated externally using objective measures (e.g., oral temperature); however, it does not take into account the masking effect caused by work schedule: on work days, people in general are inherently more stimulated when in fact they could (preferably) be asleep. ${ }^{34,35}$

\section{Influence of sociocultural aspects}

MEQ score distributions have also shown to be culturally influenced. For instance, mean scores were significantly different between Japanese and Korean workers, with a mean score of 56.2 for Japanese vs. 49.1 for Korean workers in all age groups, probably reflecting different social conditions and cultures between the two countries. ${ }^{36}$ Adan et al. ${ }^{37}$ studied the CSM using a sample of Spanish students, and reported that subjects with scores $\leq 21$ were classified as evening types, those with scores between 22 and 39 were classified as intermediate types, and those with scores $\geq 40$ were classified as morning types. That cross-cultural study indicated the need to apply new criteria for different group classifications (such as the 20th and 80th percentiles) so as to select moderate evening types and moderate morning types, respectively.

\section{Influence of mealtimes}

Meal timing is considered an important socioenvironmental synchronizer of circadian rhythm and influences human metabolism; the temporal distribution of food intake also has an influence on human performance. Costa et al. ${ }^{38}$ tracked usual mealtimes of 670 individuals on work and free days. The times of the two main meals showed a high stability on both work days and free days. However, breakfast time advanced progressively on free days compared with work days. Individuals classified as morning types generally eat and go to bed earlier than evening types, on work days and especially on free days. ${ }^{39,40}$

\section{The influence of age and gender}

The influence of age on the distribution of morningness and eveningness preferences was observed in many studies. ${ }^{15,28,41-43}$ These studies concluded that circadian preferences are significantly correlated with age, with increasing age associated with higher morningness scores. Moreover, there is evidence of changes in chronotype associated with development and aging. Delayed sleep times, common among teenagers, are thought to be 
attributable, at least in part, to developmental changes in the mechanisms regulating sleep timing. ${ }^{44}$ Conversely, there is a trend for people to prefer morningness in late adulthood, ${ }^{41}$ typically beginning at around 50 years of age. In relation to the original MEQ cutoff points, ${ }^{1}$ Paine et al. $^{28}$ concur with Taillard et al. ${ }^{15}$ that the they do not provide useful chronotype classification scores in middleaged adults.

Regarding gender, some studies failed to show a relationship of this variable with morningnesseveningness preferences. ${ }^{37,45,46}$ However, sex differences should be taken into account in morningness-eveningness studies assessing people with irregular work schedules. For instance, a significant difference was found between male and female students and shift-working hospital nurses. ${ }^{47}$ Among nurses, the irregular work schedule does not seem to affect morningness-eveningness preferences. Also, as shown by Motohashi ${ }^{47}$ and reported by Ishihara et al., ${ }^{48}$ female populations show a greater preference for morningness when compared with male populations Therefore, sex differences should be taken into account in morningness-eveningness studies assessing workers in various occupations.

\section{Other aspects possibly affecting the assessment of chronotypes}

The diurnal evolution of alertness can be influenced by the individual's degree of morningness. Young adults reporting being good sleepers were assessed to determine if they were morning types or evening types. The results indicated that there was a distinct difference between both chronotypes: evening types rated lower self-alertness upon waking compared with morning types. ${ }^{49}$ Moreover, subjective and objective sleepiness has been shown to be greater in evening-type subjects than in morning-type subjects, especially in the morning. ${ }^{50-52}$

It is important to note that, in all instruments, questions are predominantly subjective, relating sleep and activity times to a personal "feeling best" rhythm, ${ }^{1}$ or asking subjects to assess hypothetical situations (e.g., "Considering only your own feeling best rhythm, at what time would you get up if you were entirely free to plan your day?"). Conversely, "morningness" scores have been positively correlated with the experimentally measured timing of hormone levels during circadian rhythms, based on findings such as body temperature, melatonin, and cortisol levels. $8,10,52$ Notwithstanding, criticism of these scales are partly due to the fact that they do not explicitly assess free days and work days separately; neither do they assess individual differences in actual sleep times, or exposure to outdoor light. ${ }^{53}$ As a result, a new questionnaire has been developed by Roenneberg at al. ${ }^{23}$ to quantitatively assess the timing of sleep over a 24-hour day period (sleep phase). According to the authors, the questionnaire provides a qualitative assessment of sleep patterns rather than relying on a subjective self-rated chronotype, as is the case in the other scales.

When chronotype assessment is performed using subjective questions or based on mid-sleep times within a 24-hour day period, an estimate of a person's sleep phase is obtained. However, an objective measurement of the internal phase is still needed to help improve our understanding of how genetic or molecular elements influence oscillations in circadian rhythms and result in interindividual differences in human beings. Some studies try to use a clock gene expression in tissue cultures obtained from skin biopsies to measure interindividual differences in circadian clock outputs. ${ }^{54,55}$ However, it remains to be known whether this technique can measure an individual's internal phase, or even confirm whether someone is reporting their actual morningness-eveningness preferences, since clock gene expression may be considered to be a different dimension of the same phenomenon.

\section{Trends that can be derived from this review}

Some limitations of the understanding of chronotypes in the fields of psychology and psychiatry reflect controversies related to diagnosis and classification. There are, in the current literature, controversial views of the morningness-eveningness dimension, or of a category of abnormal behavior, and also of how such behavior can be modified with development. ${ }^{56-61}$ If MEQ scores or sleep phases are used as continuous variables, chronotypes will be assessed and categorized into at least three groups, namely, morning, intermediate, and evening types. Conversely, if chronotypes are seen as a common behavior to be measured, there is no point in establishing cutoff points to define an abnormal situation. If seen as a dimension, chronotype assessment should involve different aspects of human behavior, as currently used in personality studies. In this scenario, instruments that assess only one characteristic, as is the case of the MCTQ, are not good tools, because they measure phase sleep but not other behaviors related to circadian manifestations, such as appetite, activity, and alertness. Conversely, if we are looking for a relationship between external and internal synchronizers, the MEQ will be imprecise, as it does not investigate external parameters, differently from MCTQ.

Also, chronotypes do not remain uniform throughout life. In this sense, one-point assessments, not taking age into account, will not reliably describe the characteristics 
of a sample (age is an important intrinsic variable in the characterization of any sample). This limitation is also due to a non-uniform use of these concepts from a dimensional or typological perspective.

Because chronotype is an expression of the individual's internal clock, obviously it will be modified in disease processes. From a different standpoint, if it is an expression of external cues, then it will be modified by jet lag or nocturnal work. So, in the absence of other circadian variables, these characteristics could lead to a misperception of circadian rhythm.

MEQ is a well-researched and well-documented questionnaire. It is the instrument most widely used in chronobiology and sleep research (Figure 2), and it is considered to evaluate phase preferences of individuals over a 24-hour period. Therefore, until now, MEQ has been the gold standard for the assessment of chronotype, focusing on both sleep-wake information and appetite/exercise preferences, taking into account both psychological and behavioral factors when evaluating chronotypes. However, we have to be careful when using scores to rate individuals as falling into a certain chronotype category. It is essential to keep in mind that MEQ scores and results can vary according to age and gender, so caution is needed when evaluating different sample populations. Importantly, the instrument does not assess variability in individual circadian rhythm cycles, but rather takes into account personal preferences for times of the day and activity engagement when evaluating chronotype.

Even though the MEQ has been validated against biological variables and sleep diaries of morning-type and evening-type participants, it has been criticized for methodological weaknesses when used in genetic and epidemiological studies; as a result, alternative questionnaires have been developed. Considering that chronotype is a construct, we can say that sleep-wake cycles are the most important variables implicated in the characterization of this phenomenon. The more recent tool, MCTQ, was developed to iron out these limitations, and so it is predominantly used in epidemiological and genetic studies. It is also important to highlight that the MCTQ assesses one of the most important variables related to chronotype, namely, sleep-wake patterns, or the phase of sleep on both free and work days. Indeed, this variable may be considered to be a part of the chronotype construct, and we may now be able to talk about chronotype as a characteristic related to circadian rhythms. However, we should be cautious when correlating chronotype with circadian rhythm as measured by this instrument, as it does not incorporate temporal series of behaviors or biological measures throughout a given rhythm. In spite of the contributions provided by the MCTC, the instrument fails to clarify the duality found in literature between external and internal clock. Therefore, until now, no instrument is available that measures all possible interactions between the internal and external temporal organization systems.

Overall, both the MEQ and the MCTQ enable investigators to conduct epidemiological and clinical studies that can be used to test new hypotheses about the importance of life rhythm in real conditions. An example of this was our initial study, where a relationship between

\section{Publications \%}

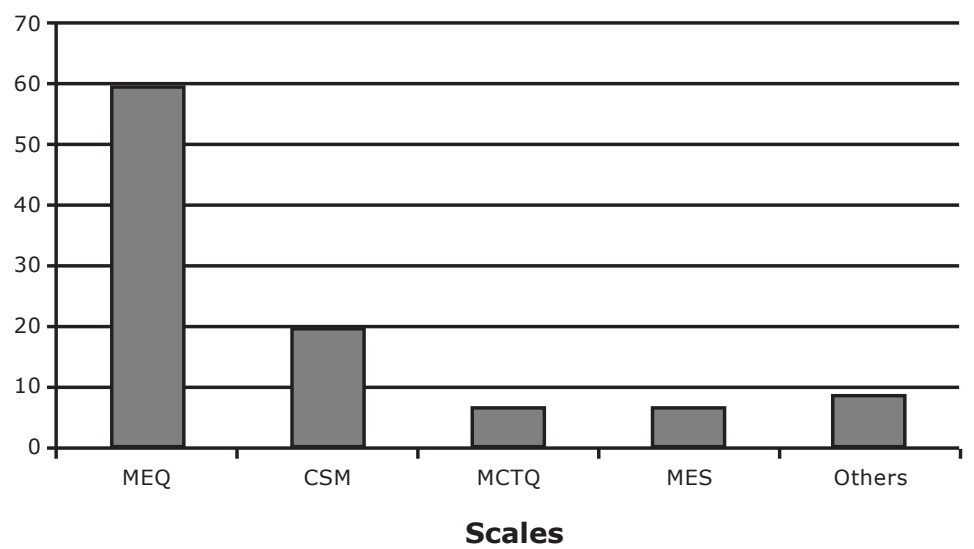

$\mathrm{MEQ}=$ Morningness-Eveningness Questionnaire; CSM = Composite Scale of Morningness; $\mathrm{MCTQ}=$ Munich Chronotype Questionnaire; MES = Morningness-Eveningness Scale for Children; Others = Basic Language Morningness (BALM), Chronotype Questionnaire (CQ), and Diurnal Type Scale (DTS), or single question.

Figure 2 - Percentage of studies published from 1976 to 2011 using different scales to evaluate chronotype, according to our literature review strategy. Each bar represents the percentage of the studies in relation the total scales used in the literature 
eveningness and depressive symptoms was found. ${ }^{62} \mathrm{We}$ later tested this hypothesis in a larger sample where the results were replicated and subsequently confirmed. Interestingly, we observed that social jet lag (defined as discrepancies between social and endogenous time, using the absolute difference in mid-sleep hours on free vs. work days) was the variable that appeared to be the most strongly correlated with this relationship, suggesting that non-optimal work times may be a factor contributing to the development of depression. ${ }^{63}$

Before we can undertake chronobiological studies in different populations, we have to confirm whether measures remain constant both in the laboratory and in real-life situations, so as to ensure that they are reliable to assess human behavior in a wide variety of contexts. Also, it is very difficult to conduct epidemiological studies to try to obtain a suitable time series of temporal data. Additionally, the variability of scores across individuals of different ages and with different or irregular work or sleepwake schedules should be accounted for when choosing an adequate instrument to evaluate chronotype. In some studies, a single self-report question was enough to categorize participants into morning preference or evening preference. We need to continue encouraging the development and use of these tools while keeping in mind their respective limitations when testing each hypothesis. These tools are informative measures to assess the behavioral, biological, and psychological elements associated with circadian phase. After all, these measures are responsible for introducing the concept of chronobiology in epidemiological and clinical research, using clinical situations as natural laboratories to improve our knowledge of temporal system regulation.

\section{Conclusion}

Based on the above, we suggest that, for investigators undertaking a desynchronization study, the MCTQ is probably the best instrument; conversely, if the goal is to assess characteristics that change under specific situations, the best is to use an instrument that measures the construct, such as the MEQ. When assessing shift work, the modified version of the MCTQ should be used to assess the real sleep phase, which is not the result of work schedule. Finally, it is important to take into account that, during medical conditions, other rhythms may appear as somewhat infra or ultradian, so the scale results will not be an expression of circadian rhythm. In this situation, an analog version of the MCTQ or sleep diaries could be used.

\section{Acknowledments}

This work was supported by Fundo de Incentivo à Pesquisa - Hospital de Clínicas de Porto Alegre (FIPEHCPA). M.P.H. received financial support from Conselho Nacional de Desenvolvimento Científico e Tecnológico (CNPq) and Fundação de Amparo à Pesquisa do Estado do Rio Grande do Sul (FAPERGS). R.L. received financial support from Programa Nacional de Pós-Doutorado Coordenação de Aperfeiçoamento de Pessoal de Nível Superior (PNPD/CAPES) - Brazil.

\section{References}

1. Horne JA, Ostberg O. A self-assessment questionnaire to determine morningness-eveningness in human circadian rhythms. Int J Chronobiol. 1976;4:97-110.

2. Benedito-Silva A, Menna-Barreto L, Cipolla-Neto J, Marques N, Tenreiro S. Latitude and social habits as determinants of the distribution of morning and evening types in Brazil. Biol Rhythm Res. 1998;29:591-7.

3. Roenneberg $\mathrm{T}$, Kuehnle $\mathrm{T}$, Juda M, Kantermann $\mathrm{T}$, Allebrandt $\mathrm{K}$, Gordijn M, Merrow M. Epidemiology of the human circadian clock. Sleep Med Rev. 2007;11:429-38.

4. Kerkhof GA. Inter-individual differences in the human circadian system: a review. Biol Psychol. 1985;20:83-112.

5. Adan A, Natale V. Gender differences in morningness-eveningness preference. Chronobiol Int 2002;19:709-20.

6. Kima S, Duekera GL, Lynn Hasherb L, Goldsteinb D. Children's time of day preference: age, gender and ethnic di $\square$ erences. Pers Individ Dif. 2002;33:1083-90.

7. Baehr EK, Revelle W, Eastman CI. Individual differences in the phase and amplitude of the human circadian temperature rhythm: with an emphasis on morningness-eveningness. J Sleep Res. 2000;9:117-27.

8. Andrade MM, Benedito-Silva AA, Menna-Barreto L. Correlations between morningness-eveningness character, sleep habits and temperature rhythm in adolescents. Braz $\mathrm{J}$ Med Biol Res. 1992;25:835-9.

9. Duffy JF, Rimmer DW, Czeisler CA. Association of intrinsic circadian period with morningness-eveningness, usual wake time, and circadian phase. Behav Neurosci. 2001;115:895-9.

10. Bailey SL, Heitkemper MM. Circadian rhythmicity of cortisol and body temperature: morningness-eveningness effects. Chronobiol Int. $2001 ; 18: 249-61$.

11. Archer SN, Robilliard DL, Skene DJ, Smits M, Williams A, Arendt J, et al. A length polymorphism in the circadian clock gene Per3 is linked to delayed sleep phase syndrome and extreme diurnal preference. Sleep. 2003;26:413-5.

12. Katzenberg D, Young T, Finn L, Lin L, King DP, Takahashi JS, et al. A CLOCK polymorphism associated with human diurnal preference. Sleep. 1998;21:569-76.

13. Pedrazzoli $M$, Ling $L$, Finn $L$, Kubin L, Young T, Katzenberg D, et al. A polymorphism in the human timeless gene is not associated with diurnal preferences in normal adults. Sleep Res Online. 2000;3:73-6.

14. Pereira DS, Tufik S, Louzada FM, Benedito-Silva AA, Lopez AR, Lemos NA, et al. Association of the length polymorphism in the human Per3 gene with the delayed sleep-phase syndrome: does latitude have an influence upon it? Sleep. 2005;28:29-32.

15. Taillard J, Philip P, Chastang JF, Bioulac B. Validation of Horne and Ostberg Morningness-Eveningness Questionnaire in a middle-aged population of French workers. J Biol Rhythms. 2004;19:76-86.

16. Adan A, Almirall H. Horne \& Ostberg Morningness-Eveningness Questionnaire: a reduced scale. Pers Individ Dif. 1991;12:241-53.

17. Caci H, Deschaux O, Adan A, Natale V. Comparing three morningness scales: age and gender effects, structure and cutoff criteria. Sleep Med. 2009;10:240-5. 
18. Natale V, Esposito MJ, Martoni M, Fabbri M. Validity of the reduced version of the Morningness-Eveningness Questionnaire. J Biol Rhythms. 2006;4:72-4.

19. Smith CS, Reilly C, Midkiff K. Evaluation of three circadian rhythm questionnaires with suggestions for an improved measure of morningness. J Appl Psychol. 1989;74:728-38.

20. Torsvall L, Akerstedt T. A diurnal type scale. Construction, consistency and validation in shift work. Scand J Work Environ Health. 1980;6:283-90.

21. Caci $H$, Nadalet L, Staccini P, Myquel M, Boyer P. Psychometric properties of the French version of the composite scale of morningness in adults. Eur Psychiatry. 1999;14:284-90.

22. Greenwood KM. Long-term stability and psychometric properties of the Composite Scale of Morningness. Ergonomics. 1994;37:377-83.

23. Roenneberg T, Wirz-Justice A, Merrow M. Life between clocks: daily temporal patterns of human chronotypes. J Biol Rhythms. 2003; 18:80-90.

24. Roenneberg T, Kuehnle T, Pramstaller PP, Ricken J, Havel M, Guth $A$, et al. A marker for the end of adolescence. Curr Biol. 2004; 14:R1038-9.

25. Allebrandt KV, Roenneberg T. The search for circadian clock components in humans: new perspectives for association studies. Braz J Med Biol Res. 2008;41:716-21.

26. Zavada A, Gordijn MC, Beersma DG, Daan S, Roenneberg T. Comparison of the Munich Chronotype Questionnaire with the Horne-Ostberg's Morningness-Eveningness Score. Chronobiol Int. 2005;22:267-78.

27. Sack RL, Auckley D, Auger RR, Carskadon MA, Wright Jr. KP, Vitiello MV, et al. Circadian rhythm sleep disorders: Part I, basic principles, shift work and jet lag disorders. An American Academy of Sleep Medicine review. Sleep. 2007;30:1460-83.

28. Paine SJ, Gander PH, Travier N. The epidemiology of morningnesseveningness: influence of age, gender, ethnicity, and socioeconomic factors in adults (30-49 years). J Biol Rhythms. 2006;21:68-76.

29. Smith C, Folkard S, Schmieder RA, Parra LF, Spelten E, Almiral H, et al. Investigation of morning-evening orientation in six countries using the preferences scale. Pers Individ Dif. 2002;32:949-68.

30. Martynhak BJ, Louzada FM, Pedrazzoli M, Araujo JF. Does the chronotype classification need to be updated? Preliminary findings. Chronobiol Int. 2010;27:1329-34.

31. Korczak AL, Martynhak BJ, Pedrazzoli M, Brito AF, Louzada FM. Influence of chronotype and social zeitgebers on sleep/wake patterns. Braz J Med Biol Res. 2008;41:914-9.

32. Adan $A$, Almirall $H$. The influence of age, work schedule and personality on morningness dimension. Int J Psychophysiol. 1992;12:95-9.

33. Campos M, Martino M. Chronobiologic aspects of sleep-wake cycle and anxiety levels of nurses working on different shifts. Rev Esc Enferm USP. 2004;38:415-21.

34. Mitchell PJ, Hoese EK, Liu L, Fogg LF, Eastman CI. Conflicting bright light exposure during night shifts impedes circadian adaptation. J Biol Rhythms. 1997;12:5-15.

35. Petru R, Wittmann M, Nowak D, Birkholz B, Angerer P. Effects of working permanent night shifts and two shifts on cognitive and psychomotor performance. Int Arch Occup Environ Health. 2005; 78:109-16.

36. Park YM, Matsumoto K, Seo YJ, Shinkoda H, Park KP. Effects of aging on morningness-eveningness and sleep habits in Korean and Japanese workers. Psychiatry Clin Neurosci. 1998;52:245-6.

37. Adan A, Caci $H$, Prat G. Reliability of the Spanish version of the Composite Scale of Morningness. Eur Psychiatry. 2005;20:503-9.

38. Costa G, Lievore F, Casaletti G, Gaffuri E, Folkard S. Circadian characteristics influencing interindividual differences in tolerance and adjustment to shiftwork. Ergonomics. 1989;32:373-85.

39. Nakade M, Takeuchi $\mathrm{H}$, Taniwaki N, Noji T, Harada T. An integrated effect of protein intake at breakfast and morning exposure to sunlight on the circadian typology in Japanese infants aged 2-6 years. J Physiol Anthropol. 2009;28:239-45.

40. Fleig D, Randler C. Association between chronotype and diet in adolescents based on food logs. Eat Behav. 2009;10:115-8.

41. Carrier J, Monk TH, Buysse DJ, Kupfer DJ. Sleep and morningnesseveningness in the 'middle' years of life (20-59 y). J Sleep Res. $1997 ; 6: 230-7$
42. Duffy JF, Czeisler CA. Age-related change in the relationship between circadian period, circadian phase, and diurnal preference in humans. Neurosci Lett. 2002;318:117-20.

43. Monk TH, Kupfer DJ. Which aspects of morningness-eveningness change with age? J Biol Rhythms. 2007;22:278-80.

44. Carskadon MA, Vieira C, Acebo C. Association between puberty and delayed phase preference. Sleep. 1993;16:258-62.

45. Russo PM, Bruni O, Lucidi F, Ferri R, Violani C. Sleep habits and circadian preference in Italian children and adolescents. J Sleep Res. 2007;16:163-9.

46. BaHammam AS, Almistehi W, Albatli A, AIShaya S. Distribution of chronotypes in a large sample of young adult Saudis. Ann Saudi Med. 2011;31:183-6.

47. Motohashi Y. Sex difference in the morningness-eveningness preference in student and hospital nurse samples. Ind Health. 1988;26:245-9.

48. Ishihara K, Miyasita A, Inugami M, Fukuda K, Miyata Y. Differences in sleep-wake habits and EEG sleep variables between active morning and evening subjects. Sleep. 1987;10:330-42.

49. Clodore M, Benoit O, Foret J, Touitou Y, Touron N, Bouard G, et al. Early rising or delayed bedtime: which is better for a short night's sleep? Eur ] Appl Physiol Occup Physiol. 1987;56:403-11.

50. Matchock RL, Mordkoff JT. Chronotype and time-of-day influences on the alerting, orienting, and executive components of attention. Exp Brain Res. 2009;192:189-98.

51. Volk S, Dyroff J, Georgi K, Pflug B. Subjective sleepiness and physiological sleep tendency in healthy young morning and evening subjects. J Sleep Res. 1994;3:138-43.

52. Dijk DJ, Duffy JF. Circadian regulation of human sleep and age-related changes in its timing, consolidation and EEG characteristics. Ann Med. 1999;31:130-40.

53. Roenneberg T, Merrow M. Entrainment of the human circadian clock. Cold Spring Harb Symp Quant Biol. 2007;72:293-9.

54. Brown SA, Fleury-Olela F, Nagoshi E, Hauser C, Juge C, Meier CA, et al. The period length of fibroblast circadian gene expression varies widely among human individuals. PLoS Biol. 2005;3:e338.

55. Pagani L, Schmitt K, Meier F, Izakovic J, Roemer K, Viola A, et al. Serum factors in older individuals change cellular clock properties. Proc Natl Acad Sci U S A. 2011;108:7218-23.

56. Satoh K, Mishima K, Inoue Y, Ebisawa T, Shimizu T. Two pedigrees of familial advanced sleep phase syndrome in Japan. Sleep. 2003;26:416-7.

57. Wyatt JK, Stepanski EJ, Kirkby J. Circadian phase in delayed sleep phase syndrome: predictors and temporal stability across multiple assessments. Sleep. 2006;29:1075-80.

58. Ahn YM, Chang J, Joo YH, Kim SC, Lee KY, Kim YS. Chronotype distribution in bipolar I disorder and schizophrenia in a Korean sample. Bipolar Disord. 2008;10:271-5.

59. Ferraz E, Borges MC, Vianna EO. Influence of nocturnal asthma on chronotype. J Asthma. 2008;45:911-5.

60. Wood J, Birmaher B, Axelson D, Ehmann M, Kalas C, Monk K, et al. Replicable differences in preferred circadian phase between bipolar disorder patients and control individuals. Psychiatry Res. 2009;166:201-9.

61. Hofstra WA, Gordijn MC, van Hemert-van der Poel JC, van der Palen J, De Weerd AW. Chronotypes and subjective sleep parameters in epilepsy patients: a large questionnaire study. Chronobiol Int. 2010;27:1271-86.

62. Hidalgo MP, Caumo W, Posser M, Coccaro SB, Camozzato AL, Chaves ML. Relationship between depressive mood and chronotype in healthy subjects. Psychiatry Clin Neurosci. 2009;63:283-90.

63. Levandovski R, Dantas G, Fernandes L, Caumo W, Torres I, Roenneberg $\mathrm{T}$, et al. Depression scores associate with chronotype and social jetlag in a rural population. Chronobiol Int. 2011;28:771-8.

\section{Correspondence}

Rosa Levandovski

Laboratório de Cronobiologia, Hospital de Clínicas de Porto

Alegre (HCPA/UFRGS)

Centro de Pesquisa Experimental

Rua Ramiro Barcelos 2350, sala 12107

90035-903 - Porto Alegre, RS - Brazil

Tel. : +55-51-3359-8849

Fax: +55-51-3359-8761

E-mail: rosa.levandovski@gmail.com 